\title{
Spiritual Influence Towards Relapse in Opioid Addicts in Therapy
}

\author{
Nurulhuda $M H^{1}$, Najwa Haneem $M^{1}$, Khairi $C M^{1}$, Norwati $D^{1}$, Aniza $A A^{1}$ \\ ${ }^{1}$ Faculty of Medicine, Universiti Sultan Zainal Abidin, Kuala Terengganu, Malaysia.
}

\begin{abstract}
Introduction: Substance abuse is both a social and public health problem with a substantial burden to society. Opioid dependence results in unemployment, crimes, family disruption, and transmission of diseases. In Malaysia, methadone maintenance therapy (MMT) has been introduced as a harm reduction method. However, relapse during treatment remains an issue to be resolved that hinders successful outcome in the therapy. Spirituality in the treatment of substance abuse disorders has yet to be fully explored. This study aims to examine how MMT clients who relapsed perceive spiritual deficits as an influence and association of spiritual practice with relapse.

Methods: This is a cross-sectional study done from June-July 2016. All MMT clients undergoing therapy at 3 treatment centers in Terengganu, Malaysia who fulfilled the inclusion and exclusion criteria and consented were included in the study. A semi-structured questionnaire was filled via face to face interview and spiritual practice was assessed using Hatta Islamic Religiosity Scale. 121 questionnaires were assessed and data was analyzed using SPSS version 22 for quantitative data.

Results: All respondents were males of Malay race and Islamic religion. Current relapse, defined as any episode of intake of opioid for the past one month after a period of abstinence was $34 \%$. Only three out of 42 clients who relapsed had some spirituality theme in their perceived cause of their relapse. However, a significant majority of those relapsed had a spiritual practice score of less than the mean practice score.

Conclusion: Relapse in opioid addiction remains high in those receiving MMT in Terengganu, Malaysia. Spirituality may have a subconscious influence towards relapse in addiction in MMT clients. Further effort should be taken to inculcate spirituality intervention effective to prevent relapse which may contribute towards achieving a more successful therapy outcomes.
\end{abstract}

Keywords: Spirituality, Relapse, Methadone Maintenance Therapy

\section{BACKGROUND AND AIMS}

Substance abuse is both a social and public health problem with a substantial burden to society. Opioid dependence, with an estimated prevalence of 16.5 million in 2013 worldwide ${ }^{1}$ carries a high cost to society by resulting in unemployment, crimes and family disruption ${ }^{2}$ not to mention transmission of diseases such as HIV and Hepatitis C. In Malaysia, there is an estimated 400000 to 800000 drug users ${ }^{3}$, with 234000 heroine abusers ${ }^{4}$. It is therefore important to develop effective treatments for this problem, and evaluate these treatments by identifying determinants of successful outcomes such as abstinence of heroin in order to carry out a more effective intervention.

Many of those who work in the substance addiction treatment field has viewed the use of spiritual concepts in the treatment of drug addiction as one of the clearest demonstration of the value of spirituality and seen this construct as one of the

Nurulhuda Mat Hassan

Faculty of Medicine,

Kampus Kota,

Universiti Sultan Zainal Abidin,

20400 Kuala Terengganu, Malaysia.

Email:nurulhudamh@unisza.edu.my main curative factor in recovery ${ }^{5}$. It has been found that spirituality and religiosity to be protective towards substance abuse. A review of 185 studies reported that $84 \%$ of studies found an inverse relationship of substance abuse with religiosity ${ }^{6}$. However, majority of these studies used religiosity using a Judeo- Christianity instrumentation and worldview.

It is crucial that targeted interventions in substance abuse concur with the local substance abuse norms and practices. Some studies have been done in Malaysia regarding the methadone maintenance therapy, but the focus of the previous studies was more on the retention rate and patient factors affecting the retention rate. To ensure the success of therapy, it is important that we can determine what are the factors significantly influence the opioid addicts undergoing Methadone Maintenance Therapy (MMT) to relapse into taking of heroin despite being in the therapy, including spiritual influence. There are lack of local studies assessing relapse and also spirituality in the treatment of substance abuse. This study aims to determine the prevalence of relapse in opioid addicts compliant to MMT (MMT clients); to examine how those who relapsed perceive spiritual deficits as an influence and determine the association of spiritual practice with relapse. 


\section{METHODS}

This is a mixed method cross-sectional study done from June to July 2016. Samples were recruited from opioid addicts undergoing MMT (MMT clients) at 3 primary care outpatient treatment centers in Kuala Nerus district, Terengganu, which is situated in the northeastern Peninsular Malaysia. Malay Muslim constitutes of more than $96 \%$ of the state's population.

Sample size calculation to determine the prevalence relapse among clients involved in methadone maintenance therapy was done using single proportion formula.

$\mathrm{n}=(\mathrm{Z} / \Delta)^{2} \mathrm{P}(1-\mathrm{P})$

$\mathrm{n}=$ Minimum required sample size

$Z=$ Value of standard normal distribution $=1.96$

$\mathrm{D}=$ Precision $=0.05$

$\mathrm{P}=$ Prevalence of relapse from literature

The prevalence of relapse was $8 \%^{7}$ hence minimum required sample size was 113 . Considering non response rate of $10 \%$, the sample size calculated was 124.

All MMT clients who came for treatment within the study period who fulfilled the criteria of being 6 months in therapy with a period of abstinence of more than a month and consented were interviewed face-to-face using a semi-structured questionnaire. Clients were defined as having current relapse when they admit of taking any illicit heroin for the past one month or have the evidence of positive urine for heroin or new injection mark; with previously being abstinent of heroin during therapy of at least one month by having a negative urine test for heroin.

Subjects identified having relapsed were interviewed on their subjective reasoning for their relapse, to identify the specific themes underlying their reasoning, experiences and social environment leading to relapse. The interviews were recorded and analyzed using systematic case comparison using Atlas.ti to come up with the results.

Spiritual practice was assessed using Hatta Islamic Religiosity Scale. 121 questionnaires were assessed and data was analyzed using SPSS version 22 for quantitative data. Chi square was used to analyze the association between relapse and practice score and relapse and knowledge score. Ethical clearance was obtained from National Medical Research Ethics Committee (NMRR Reference Number: 5-230727817).

\section{Hatta Islamic Religiosity Scale (HIRS) ${ }^{8}$}

This is a valid and reliable twenty-seven items scale utilized to measure Islamic knowledge and practice among Muslim adults and adolescents in the state of Selangor, Malaysia. Two independent reliability studies were conducted among a total of 286 adolescents and young adults. Inter-rater reliability for the total HIRS score was found to be high in both studies $(0.891$ and 0.90$)$. The measure is also valid in that it is able to discriminate the religiosity of two groups, for example between the tahfiz and the delinquent youth groups $(p<0.05)^{8}$. However, it is worthy to note that HIRS do not attempt to measure the faith (piousness) of the subjects, as the matter of faith is immeasurable by any questionnaires or human inventory ${ }^{9}$.

\section{RESULTS}

Response rate was 97.6\%. All respondents were males of Malay race and of Islamic religion. Mean age was 36.2. Mean duration in MMT was 1.4 years. Current relapse, defined as any episode of intake of heroin for the past one month after a period of abstinence was $34.4 \%$. Of those relapsed, majority (78.6\%) had Hepatitis C, $19.0 \%$ had HIV and $7 \%$ had Hepatitis B.

Mean HIRS Islamic knowledge and practice scores were $6.81 \pm 3.29$ and $12.87 \pm 3.43$. There was no assoication between Islamic knowledge and relapse. Table 1 shows the significant association of relapse with practice score, where a significant portion $(65.1 \%)$ of those who relapsed had a less than mean practice score $(p=0.03)$.

Table I: Association Between Relapse and Practice Score

\begin{tabular}{llll}
\hline & $\begin{array}{l}\text { Relapse } \\
(\mathrm{n}=43)\end{array}$ & $\begin{array}{l}\text { No } \\
\text { relapse } \\
(\mathrm{n}=78)\end{array}$ & $\mathrm{P}$ \\
\hline More than mean & 15 & $\begin{array}{l}42 \\
(53.8 \%)\end{array}$ & 0.03 \\
& $(34.9 \%)$ & $\begin{array}{l}36 \\
(46.2 \%)\end{array}$ \\
\hline
\end{tabular}

Likelihood ratio: 9.03

\section{Qualitative Reasoning for Relapse: Spirituality}

Among 43 relapsed, only 3 (7\%) perceived having some spiritual problems underlying their relapse. They stated the following:

I cannot control myself. Most probably there's satanic influence in me (at that time). My faith was not too strong ( $R$ 5, 29 years old)

Why I took it (at that time) was that..l don't know, maybe my 'iman' (faith) was not strong, right? (R36, 32 years old)

I took it because I was unable to resist the urge. Moreover, my faith was not strong. (M40, 43 years old, )

Only one respondent was able to relate their practice of religion with their faith. Such is the statement:

That's why I said, (my) faith was not strong. If my faith is strong, this would not have happened. When my faith is strong, I remember to pray. When I am not (having strong faith), I did not (pray) (R36, 32 years old)

However, most of the subjects who relapse blamed the social environment which was due to the celebration of 'Eidulfitri', which was a celebration 
in the Muslim calendar. Among the statements given was:

I wanted to celebrate, (and) to feel happy. It was a joyous occasion where I wanted to celebrate my friends who come back from outside (the state) (R4, 28 years old)

It was Eid. I wanted to feel happy (and) to enjoy. Moreover I feel that I miss it (heroin) (R35, 46 years old)

\section{DISCUSSION \\ Addiction and spirituality}

Previous research has shown that addiction was associated with significant brain changes in particular related to brain reward circuitry. Area of limbic system governing emotions and prefrontal cortex governing cognition and social behaviours were directly affected. As the treatment instituted and continued, the person showed improved behaviours and better thinking process. Psychosocial components as part of comprehensive addiction treatments will address issues such as morality, spirituality and religion ${ }^{10}$.

Religion and spirituality promotes better health behaviours and is associated with less drug use and safer sexual practices in the majority of studies which examined these relationships ${ }^{6}$. Studies showing Muslim with strong practices of religion in the form of prayers were more likely to abstain from extramarital sex, faithful in marriages and avoid alcohol and narcotics ${ }^{11}$.

\section{Relapse in MMT}

Most studies have suggested that relapse is common after treatment for drug addiction. A ten-year prospective follow-up study have showed that approximately one-third of clients who were in full remission relapsed in the first year ${ }^{12}$, which is similar to the results of this study. A few other studies show a much less relapse percentage of 8 to $10 \%^{13,14}$ and some studies show a much higher relapse of $64 \%{ }^{15}$. However, comparing relapse between studies must take into account the definition of relapse used in the study as it may indeed be the cause of discrepancy.

\section{Spirituality: Contribution in Relapse}

Spirituality can be best understood as comprised of multiple dimensions including: behavior and practices; beliefs; motivations and values; and, subjective experience ${ }^{16}$. It can be studied through the activities of religious organizations, nonreligious organizations and statement of belief ${ }^{17}$. Increased spiritual practices have been associated with improved treatment outcome in addiction therapy ${ }^{18}$.

This study have shown that non-relapsed individuals apparently show more evidence of spirituality than those who relapsed, which has been found in a few other studies abroad ${ }^{19}$. However, this study have also demonstrated that majority of those relapsed did not consider their lack of spirituality or religiosity to be the contributing factor in their relapse. This lack of awareness is indeed dangerous and underscores the need to have interventions that highlights this subconscious relationship between spirituality and relapse. Bringing this into the conscious mind may help in the individuals to take action to increase their spirituality and religious practice which may lead to better outcome in their treatment.

Association of happiness or enjoyment during a joyous occasion to taking heroin indeed need to be addressed in the counselling session during MMT. It may help to prevent relapse if this association could be removed and attached to a spiritual or religious activity. Further effort to inculcate this as well as the other spiritual elements in therapy would indeed lead to a better outcome in MMT and further reduce the burden of this social ill towards the society.

This study limitations includes a cross-sectional design, relying on recall information by the respondents which is subjected to recall bias and non-adjustment of probable confounding factors towards religious practice and knowledge scores.

\section{CONCLUSION}

Relapse in opioid addiction remains high in those receiving MMT in Terengganu, Malaysia. Spirituality may have a subconscious influence towards relapse in addiction in MMT. Further effort should be taken to inculcate spirituality intervention effective to prevent relapse which may contribute towards achieving a more successful therapy outcomes.

\section{Conflict Of Interest}

The authors declare no conflict of interest.

\section{ACKNOWLEDGEMENT}

This study has been funded by short term grant by University Sultan Zainal Abidin (UniSZA/2016/DPU/13). The support is greatly appreciated.

\section{REFERENCES}

1. United Nations Office on Drugs Crime. World Drug Report 2013 - May 2013, UNODC, Vienna, Austria. Available from: http: / /www.unodc.org/wdr/index.html

2. World Health Organization, United Nations Office on Drugs and Crime, Joint United Nations Programme on HIV/AIDS. WHO/UNODC/UNAIDS position paper: Substitution maintenance therapy in the management of opioid dependence and HIV/AIDS prevention, 2004, Geneva, Switzerland. Available from:

http://www.who.int/substance_abuse/public ations/ en/PositionPaper_English.pdf 
3. Ministry of Health, Malaysia. National clinical guidelines \& procedures for the use of buprenorphine and buprenorphine/naloxone in the treatment of opioid dependence in Malaysia, 2006.

4. Ruger JP, Chawarski M, Mazlan M, Luekens C, $\mathrm{Ng} \mathrm{N}$, Schottenfeld R. Costs of addressing heroin addiction in Malaysia and 32 comparable countries worldwide. Health Serv Res 2012; 47(2): 865-87.

5. Piedmont, R.L. 2001. Spiritual transcendence and the scientific study of spirituality. Journal of Rehabilitation, 67, 4-14.

6. Koenig, H.G., 2012. Religion, Spirituality and Health The Research and Clinical Implications. ISRN Psychiatry, 2012: 278730

7. Kaur, S., Mohd, H. B., \& Mohamed, M. N. (2009). Projek perintis program rawatan terapi gantian (RTG) menggunakan methadone di Pusat Khidmat AADK. Journal Antidadah Malaysia5(1), 1-30

8. Salleh H.M., M.H. Shaharom, M.I.M. Nor K Shamsuddin, K. Kassim, R. Ismail and N. Moktar. Hatta Islamic Religiosity Scale 1996(HIRS96) - A Reliability and Validity Study Malaysian Journal of Psychiatry Volume 7, No. 1, 1999

9. Shaharom, M.H., 2014. Islamic Psycho-Spiritual Religiosity Therapy (PST): Panacea for the Drug Addict. FIMA year book, 2014, pp: 155-62.

10. Volkow ND, Baier RD and Goldstein RZ. Neuron, 2011,69, 599-602

11. Kagimu, M., D. Guwatudde, C. Rwabukwali, S. Kaye, Y. Walakira and D. Ainomugisha, 2013. Religiosity for Promotion of Behaviors Likely to Reduce New HIV Infections in Uganda: A Study among Muslim Youth in Wakiso District. Journal of Religion and Health, 52: 1211-27.

12. Xie H, McHugo GJ, Fox MB, Drake RE. 2005. Substance abuse relapse in a ten-year prospective follow-up of clients with mental and substance use disorders. Psychiatr Serv 56: 1282-1287.

13. Mohamad et al. Better retention of Malaysian opiate dependents treated with high dose methadone in methadone maintenance therapy. Harm Reduction Journal 2010, 7:30

14. George P Outcomes from the Malaysian Arm of The International Survey Informing Greater Insights in Opioid Dependence Treatment (INSIGHT) Project. Med J Malaysia Vol 70 No 2 April 2015

15. Mohammadpoorasl A, Fakhari A, Akbari $\mathrm{H}$, Karimi F, Arshadi Bostanabad M, et al. 2012. Addiction Relapse and Its Predictors: A Prospective Study. J Addict Res Ther 3:122. doi:10.4172/2155-6105.1000122

16. Miller, W.R. 2003. Spirituality, treatment, and recovery. In: M. Galanter, (Ed), Recent developments in alcoholism. Volume 16: Research on alcoholism treatment: Methodology/psychosocial treatment, selected treatment topics, research priorities (pp. 391404). New York: Kluwer Academic.

17. Baker, D. C. 2003. Studies of the inner life:
The impact of spirituality on quality of life.Quality of Life Research,12(1), 51-5

18. Carter. T. M. 1998. The effects of spiritual practices on recovery from substance abuse. Journal of Psychiaty and Mental HealthNursing. 5. 409-413

19. Jarusiewicz, B. 2000. Spirituality and addiction: relationship to recovery. Alcoholism Treatment Quarterly, 18(4), 99-110. 